\title{
Talent Retention of Female Faculties In India
}

\author{
Sandeep Saxena \\ Department of Mgt., Gautam Buddha Technical University, Lucknow, India
}

\begin{abstract}
The role of the teachers acquires significance in shaping society and in bringing revolutionary changes in the development of the country. But in India burgeoning problem is the retention and proper development of talent. The main thing of this paper is female talent management and development of the proper talent pool. This paper seeks to understand and analyze the causes of the high attrition rate of female employees in the technical institutes. This tries to diagnose the malady and prescribe the remedial solutions. This paper studies the female job retention in technical institutes who work hard at irregular hours in the midst of their domestic caring responsibility. It was based on the structured survey through a questionnaire, with female faculties who work in major cities in India. The Findings suggest a need for change both in organizational and work policies for female job retention.
\end{abstract}

Keywords: Talent management, Retention, Talent pool, Job attrition, Potentials and skills

\section{Introduction}

In our Indian culture, a teacher is given utmost importance. A teacher is not only teaches the students about things in the world, educates them and shares with them his knowledge and wisdom but also acts as a spiritual guide for his students because he leads them on the path of truth, light, eternal wisdom and everlasting virtues. Now in India, female talents play a vital role in nation-building. In India, the female teachers face great challenges today. Today the world is of science, new inventions and competitions to excel over the other. We can be proud to be a part of our great country but the world has shrunk today to a common platform on the basis of higher education and learning but female talent retention is very low in India. Female talent shortage is very big problem in education field. Female teachers leave easily the job due to family problems or organization cultures. If faculty leaves the institute in midsession, students will face many problems. It creates a big void in the mindsets of the students.

\section{Talent Management}

Talent management incorporates attracting, retaining and developing the talent pool available to an organization in association with the other functions of management, so that the organization is never rendered bereft of expertise. Management experts have defined talent as the people who have high potential and skills or those who can successfully lead transformation and change in the organization. Talent management is a systematic process of identifying, assessing, developing and retaining people with critical knowledge, skills and competencies. After talent acquisition and talent management, talent/job retention is the next most important issue on any human resource agenda. Competence, capability and talents are human assets of organizations. At the workplace, capability could mean member's readiness to seek, undertake and carry out challenging work assignments. The role of the faculties acquires significance in shaping society and bringing revolutionary changes in development in India. The assumption that a high level of job retention and job satisfaction leads to high productivity came to be popularly accepted since it filled into the value system of the human relations movement and also because some resource data supported this point.

This paper has shown that the Academics are a male-dominated field in which many structural and cultural factors contribute to women's disadvantage. The low percentage of women is working in the institutes.

The major aspects of female talent management practiced within an organization must consistently include:

- Performance management

- Leadership development

- Workforce planning/identifying talent gaps

- Recruiting

The retention of female teacher's community in educational system especially individual institutes is necessary for the effective and proper use of the resources for rendering maximum service to society through building up the future human-resource pool of the India. Talent management refers to the anticipation of required human capital the organization needs at the time then setting a plan to meet those needs. Talent management in this context does not refer to the management of entertainers. Companies engaging in a talent management strategy shift the responsibility of employees from the human resources department to all managers throughout the organization. The process of attracting and retaining profitable employees, as it is increasingly 
more competitive between firms and of strategic importance, has come to be known as "the war for talent" Talent management is also known as HCM (Human Capital Management).

\section{Female Employee Expectations}

There is a list of employee expectation,

1) Freedom to express and create.

2) Team approach work closely with others for good result.

3) Less tolerance to non - performance of coworkers.

4) An opportunity to move up quickly if talented no matter what the age or background is.

5) Good financial recognition for contribution.

The term "talent management" means different things to different organizations. To some it is about the management of high-worth individuals or "the talented" whilst to others it is about how talent is managed generally - i.e. on the assumption that all people have talent which should be identified and liberated.

With large numbers of employees reaching retirement and average to above-average industry growth rates, this industry will experience increases in demand and competition for top talent. Our research shows that employers, including Education Institutions, can do a better job of leveraging their employee benefits plans in an effort to retain employees.

Talent management is a term that emerged in the 1990s to incorporate developments in Human Resources Management which placed more of an emphasis on the management of human resources or talent. The term was coined by David Watkins of Soft cape published in an article in 1998; however the connection between human resource development and organizational effectiveness has been established since the 1970s.Talent management is part of the Evolution of Talent Measurement Technologies.

The issue with many companies today is that their organizations put tremendous effort into attracting employees to their company, but spend little time into retaining and developing talent A talent management system must be worked into the business strategy and implemented in daily processes throughout the company as a whole. It cannot be left solely to the human resources department to attract and retain employees, but rather must be practiced at all levels of the organization. The business strategy must include responsibilities for line managers to develop the skills of their immediate subordinates. Divisions within the company should be openly sharing information with other departments in order for employees to gain knowledge of the overall organizational objectives. Companies that focus on developing their talent integrate plans and processes to track and manage their employee talent, including the following:

- Sourcing, attracting, recruiting and on boarding qualified candidates with competitive backgrounds.

- Managing and defining competitive salaries.

- Training and development opportunities

- Performance management processes.

- Retention programs.

- Promotion and transitioning.

\section{IV. $\quad$ Female Employee Empowerment}

It is a technique of involving employees in their work though the process of inclusion. Empowerment encourages employees to become innovators and managers of their own work, and it involves them in their jobs in ways that give them more control and autonomous decision-making capabilities. As described by one manager, employee empowerment involves "pushing down decision-making responsibility to those close to internal and external customers."

While defining empowerment can become the first step to achieving it, in order for empowerment to grow and thrive, organizations must encourage these conditions:

Participation: Employees must be encouraged to take control of their work tasks. Employees, in turn, must care about improving their work process and interpersonal work relationships.

Innovation: The environment must be receptive to people with innovative ideas and encourages people to explore new paths and to take reasonable risks at reasonable costs. An empowered environment is created when curiosity is as highly regarded as is technical expertise.

Access to information: Employees must have access to a wide range of information. Involved individuals decide what kind of information they need for performing their jobs.

Accountability: Empowerment does not involve being able to do whatever you want. Empowered employees should be held accountable for their behavior towards others, producing agreed-on results, achieving credibility, and operating with a positive approach.

The talent management strategy may be supported by technology such as HRIS (HR Information Systems) or HRMS (HR Management Systems). Modern techniques also use Competency-based management methodologies to capture and utilize competencies appropriate to strategically drive an organization's long term plans. 
Talent management is a term that emerged in the 1990s to incorporate developments in Human Resources Management which placed more of an emphasis on the management of human resources or talent. The term was coined by David Watkins of Softscape published in an article in 1998, and further defined in the book "Talent Management Systems" in 2004.

The challenge with employee benefits is viewing them as an investment, not a cost. For example, buying office equipment can be hugely expensive, but no one blinks because it is seen as something that will generate a return. In order to see benefits this way, executives must know that they will produce a positive outcome for the company. To that end, experts agree that a purposeful and targeted approach to benefits can boost employee retention rates, which can be an enormous cost savings. Each resource in the organization plays a vital role in its success. Amongst all the available resources in an organization, human resource is the most crucial one. Managing human resources in an effective manner can lead to better chances of organizational success. A high-performance organization attaches more importance to talent and goes all out to cultivate and consolidate its talent pool. This process involves recruiting, selecting, developing and motivating competent employees in a way that they are equipped with the right skill set that helps the organization in the attainment of its goals.

Companies that engage in talent management (Human Capital Management) are strategic and deliberate in how they source, attract, select, train, develop, retain, promote, and move employees through the organization. Research done on the value of such systems implemented within companies consistently uncovers benefits in these critical economic areas: revenue, customer satisfaction, quality, productivity, cost, cycle time, and market capitalization. The mindset of this more personal human resources approach seeks not only to hire the most qualified and valuable employees but also to put a strong emphasis on retention.

Organizations are in the process of changing over to new performance-appraisal practices for better performance by linking performance with rewards and motivating high performers. These are becoming a priority in organizations as an important contributor to effective talent management (Bhandarker 2003).

Retention challenges: these are faced at two levels for female employees: Individual and Organizational.

At the individual level, the following reasons pose retention challenges:

Career growth: Career growth is being increasingly seen as a variety of exposure - cross-function, cross-industry and cross-geography. Good examples are people working in manufacturing and oil companies moving to the Middle East and Africa or expatriates from mature retail markets moving to India.

Globalize work environment: Increased connectivity has led to work environments becoming more global.

Shortened time horizons: Generational attitude is being redefined in terms of shortened time horizons for "staying" in an organization or organizational "loyalty." Research suggests that employees will be changing 10 to 15 jobs in 30 years, which translates into a span of two to three years per job. Peer comparisons: Comparisons with peers are becoming a greater influence due to increased connectivity on various social platforms. Employees are constantly looking for "greener pastures." Work-life balance: Emphasis on work-life balance is greater than ever.

Reasons for challenges at the 'Organizational' and 'Industry' levels are:

Poor people management skills: Accelerated growth of people managers to senior management due to exponential development in some sectors has led to a growing pool of managers with questionable people management skills. Employees tend to leave their managers, hence adding to attrition.

Paucity of talent: Organizations in the same domain are scrambling for the same talent with no perceptible differentiation.

Unsound hiring practices: Dilution of ethical hiring practices due to the great need to "make the numbers."

The main objectives were:

\section{Objectives Of The Study}

a) To understand the concept of talent management

b) To analyze the factors that lead to the high turnover rate of female faculty

c) To suggest ways to reduce the turnover rate of female faculty

\section{Research Methodology}

6.1 Sampling

It was a descriptive study therefore, survey was considered appropriate for this study. Faculty of engineering and technological institute was taken as a sample. Survey has been done in the major cities of India. In this survey, a questionnaire on five points (Likert Scale) was used for the collection of data .A questionnaire was developed on five point (likert) to know the opinion of female faculty members. The finalized research tool 
Talent Retention Of Female Faculties In India

was administered on the respective sample for the collection of data. Collected data was analyzed through percentage and mean score. Responses of 70 out Of 75 respondents were interpreted and presented in percentage. The sample size was purposely kept small due to the constraint of time and resources

6.2 Data Analysis

TABLE 1

\begin{tabular}{|l|l|}
\hline AGE (YEARS) & NO. OF FEMALE FACULTY \\
\hline $20-30$ & 20 \\
\hline $30-40$ & 30 \\
\hline $40-50$ & 15 \\
\hline 50 ABOVE & 5 \\
\hline
\end{tabular}

TABLE 2

\begin{tabular}{|l|l|}
\hline LENGTH OF SERVICE (YEARS) & NO. OF FEMALE FACULTY \\
\hline $0-2$ & 10 \\
\hline $2-5$ & 25 \\
\hline MORE THAN 5 & 35 \\
\hline
\end{tabular}

TABLE 3

\begin{tabular}{|l|l|}
\hline \multicolumn{1}{|c|}{ INTENTED TIME IN THIS INSTITUTE (YEARS) } & NO. OF FEMALE FACULTY \\
\hline $0-2$ & 20 \\
\hline $2-5$ & 35 \\
\hline MORE THAN 5 & 15 \\
\hline
\end{tabular}

It can be noticed from the table that most of the female employees of institutes are working with an experience of more than 2 years. Most of them have age of 30 to 40 years. The data collected through questionnaire was analyzed by using mean and percentage.

TABLE 4 ORGANIZATIONAL/INSTITUTIONAL REASONS FOR LOW TALENT RETENTION

\begin{tabular}{|l|l|l|l|l|l|l|l|l|}
\hline S. NO. & STATEMENT & $\begin{array}{l}\text { S. } \\
\text { A. }\end{array}$ & A & UNC & DA & $\begin{array}{l}\text { SD } \\
\text { A }\end{array}$ & $\begin{array}{l}\text { MEA } \\
\text { N }\end{array}$ \\
\hline 1 & Organization Culture & 40 & 20 & 0 & 05 & 05 & 86 & 4.21 \\
\hline 2 & Salary & 32 & 20 & 0 & 08 & 10 & 74.3 & 3.80 \\
\hline 3 & Workload & 25 & 35 & 0 & 05 & 05 & 86 & 4.00 \\
\hline 4 & Work Life Imbalance & 25 & 25 & 0 & 08 & 12 & 71 & 3.61 \\
\hline 5 & Organizational Politics & 35 & 15 & 0 & 12 & 08 & 71 & 3.81 \\
\hline 6 & Reward and Recognition & 22 & 20 & 0 & 18 & 10 & 60 & 3.37 \\
\hline 7 & $\begin{array}{l}\text { Lack of Career Advancement \& Growth } \\
\text { Opportunity }\end{array}$ & 28 & 22 & 0 & 10 & 10 & 71 & 3.69 \\
\hline 8 & Unsupportive Head/Senior & 22 & 28 & 0 & 08 & 12 & 71 & 3.57 \\
\hline 9 & Improper Training Facilities & 26 & 23 & 0 & 11 & 10 & 70 & 3.63 \\
\hline 10 & Poor Infrastructure & 15 & 10 & 0 & 10 & 35 & 36 & 2.43 \\
\hline 11 & $\begin{array}{l}\text { Management's Attitude Towards } \\
\text { Employee }\end{array}$ & 26 & 26 & 0 & 10 & 08 & 74 & 3.74 \\
\hline
\end{tabular}

TABLE 5

PERSONAL REASONS FOR LOW TALENT RETENTION

\begin{tabular}{|l|l|l|l|l|l|l|l|l|}
\hline S. NO. & STATEMENT & S.A. & A & UNC & DA & SDA & $\%$ & MEAN \\
\hline 1 & Family Reasons & 40 & 20 & 0 & 7 & 3 & 86 & 4.24 \\
\hline 2 & Time Schedule & 35 & 20 & 0 & 10 & 5 & 79 & 4.00 \\
\hline 3 & Distance From Residence & 28 & 21 & 0 & 15 & 6 & 70 & 3.71 \\
\hline 4 & Other Reasons & 25 & 20 & 0 & 13 & 12 & 64 & 3.47 \\
\hline
\end{tabular}

Scale value for this table is SA (Strongly Agree) =5, A (Agree) =4, UNC (Uncertain) =3, DA (Disagree) $=2$ and SDA (Strongly Disagree) $=1$ 
Through our research we found that most of the female faculties leave institute because of organization culture, workload and organizational politics TABLE 4. Organizational culture (mean 4.21) is main cause of not retention in academic job.

Work load (mean 4.00) and Organizational politics (mean 3.81) are main reason of leaving the job. Salary (mean 3.80) is not very important factor for job retention.

In the personal reasons, family liability (mean4.24) is root cause for leaving the job from TABLE 5. Family responsibilities (change in marital status /single to married, child care) are main cause of leaving the job for Indian women.

Employee retention refers to the ability of an organization to retain its employees. Indian women want flexible time schedule (mean 4.00) and less distance from home (mean 3.71). There are some other reasons (mean 3.47) like mental harassment, health problems, pregnancy etc. In overall, percentage (86\%) female faculties are agree with organizational culture, workload and family liabilities as root causes of less talent retention. When probed beyond the questionnaire, respondents expressed their view that the quality of education is going down due to their view that the entry of regionalism, casteism, politics and business motives in the educational set up.

Factors responsible for the law participation rate/ Low retention rate of Indian females:

Cultural factors were until recently of considerable importance in limiting the extent to which Indian females played on active economic role outside the home traditionally , the Indian women's place was in the home, however, the adoption of western values have recently obviated traditional restrictions.

Higher birth rate in India increases the burden of family responsibilities on Indian women.

Educational standards of Indian women have improved and they are now better equipped to seek jobs.

Economic factors are also responsible for it. This is not related to poverty but also the desire to increase standards of living and to supply children with better education. In many instances, husband's income is not sufficient because of the rising cost of living.

\section{Suggestions}

Below mentioned are few of the tools for Employee Retention:-

1. Employee Reward Program- Institute can make a provision of Monthly or Quarterly Award (depending upon the budget) for the best employee, Awarding 2 or 3 best faculties each month. The award can be in terms of gifts or money. If it is money then it should be divided into two parts, first part to be given with the next month salary and the remaining after 6 months. In this way she can be retained for 6 more months. These rewards shall be considered at the time of appraisal.

2. Career Development Program- Every individual is worried about her career. Institute can provide them conditional assistance for certain courses which are beneficial from business point of view. Conditional assistance means the institute will bear the expenses only if she gets an aggregate of certain percentage of marks.

3. Performance based Bonus- The employee always comes to know about the profit of the company which is of course based on the strategic planning of the top management and the productivity of the employee. To get more work out of the employee, institute can make a provision of Bonus.

4. Employee Referral Plan- institute can introduce Employee Referral Plan. This will reduce your cost (charges of external consultants and searching agencies) of hiring a new employee and up to an extent institute can rely on this new resource.

5. Loyalty Bonus- Institute can introduce a Loyalty Bonus Program in which it can reward employee after a successful completion of a specified period of time. This can be in the form of Money or Position. This will encourage the fellow employees as well whether they are interested in money or position, they will feel fascinated.

6. Giving a voice to the Knowledge Banks- First of all you should try to retain your workforce intact, as they are the intellectual asset of the company. And above that you can't afford losing your knowledge banks. These are the people who stabilize the process. You can involve them in some of the decisions.

7. Employee Recreation- Institute should also let your employees enjoy in a light mood. It can take its employees to a trip or for an outing every year or bi-yearly. Institute can make use of this trip as well. It can start this trip with an opening note about the management views and plans, strategies etc.

8. Gifts at some Occasions- It can give some gifts at the time of one or two festivals to the employees making them feel good and understand that the management is concerned about them.

9. Accountability- Institute should make each employee accountable so that she can also feel that she is as important as her head of department. If she will be filled with this sense, she will seldom think of leaving the company. 
10. Making the head of department effective and easily accessible- institute should make the management easily accessible so that the employee expectations can be clearly communicated to the top management, as it is impossible for the top management to reach each employee frequently.

11. Retention strategies- Every institute is very aware about the female faculties they keep. They give value their talented Female faculties and are more than eager to get rid of their trouble-making faculties.

There are some ways to retain female faculties:

1. Skill development program

2. Continuously nurturing competence and talents

3. Empowerment

4. Maintain workload and salary

5. Maintain positive mind set of faculty

6. Research and development

7. Personal effectiveness and self-development programs

8. Change management and team building programs

9. Programs on assertive skill

10. Program on conflict-management programs

A successful retention practice will help in developing a network of experienced and talented employees who can join hands in hand to take up challenges in the present and future as well.

\section{Conclusions}

This research has explored why the retention of female faculties in institutes and professions is low. This research paper shows that In India, root causes of job leaving of female faculty are family liability and organization culture. The retention of star performers is crucial for every organization, more so in the case of engineering and management institute, as they are recognized and associated with the faculty they have. Institutes pay a high price for an exodus of faculty. Female talent people have high demands in terms of the balance between her work life and personal life. In order to develop good retention plan engineering and management institute must develop suitable job-context, role context, culture and environment, compensation, faculty development programs and above all must rise above organizational politics. Gender therefore shapes the experiences of work, and has different implications for male and female employees. Normally in India, salary of women is less than men. Improve the job retention of female teachers is today's burning need in India. Women have capabilities to make a world of difference in the march of human civilization.

\section{Journal Papers}

\section{References}

[1] Adkins, C. L., Werbel, J. D., \& Farh, J. (2001). A field study of job insecurity during a financial crisis. Group \& Organization Management, 26(4), pp. 463-483.

[2] Aisenberg, N., \& Harrington, M. (1988). Women of academe: Outsiders in the sacred grove. Amherst, MA: University of Massachusetts Press.

[3] Ambrose, S., Huston, T., \& Norman, M. (2005). A qualitative method for assessing faculty satisfaction. Research in Higher Education, 46(7),pp. 803-830.

[4] Antonio, A. L., Cress, C. M., \& Astin, A. W. (1997). Faculty diversity: Faculty of color still low in numbers and ranking; But Latino/as report high job satisfaction. The Hispanic Outlook in Higher Education, 7(26),pp. 14.

[5] Astin, H., \& Davis, D. (1985). Research productivity across the life and career cycles: Facilitators and barriers for women. In M. F. Fox (Ed.), Scholarly writing and publishing: Issues, problems and solutions. pp.147-160.

[6] Hult, C., Callister, R. R., \& Sullivan, K. (2005). Is there a global warming toward women in academia? Liberal Education, 91, pp.50-57.

[7] Johnsrud, L. K., \& Heck, R. H. (1994). A university's faculty: Predicting those who will stay and those who leave. Journal for Higher Education Management, 10(1),pp. 71-84.

[8] Kyvik, S. (1990). Age and scientific productivity. Differences between fields of learning. Higher Education, 19, pp. 37-55.

[9] Laden, B. V., \& Hagedorn, L. S. (2000). Job satisfaction among faculty of color in academe: Individual survivors or institutional transformers? New Directions for Institutional Research, 105, pp. 57-66. 